\title{
Method development for the determination of manganese in wheat flour by slurry sampling flame atomic absorption spectrometry
}

\author{
Rennan G.O. Araujo, Fábio de S. Dias, Samuel M. Macedo, \\ Walter N.L. dos Santos, Sérgio L.C. Ferreira * \\ Universidade Federal da Bahia, Instituto de Química, Núcleo de Excelência em Química Analitica da Bahia, \\ Campus Universitário de Ondina, 40170-290 Salvador, Bahia, Brasil
}

Received 23 June 2005; received in revised form 25 October 2005; accepted 25 October 2005

\begin{abstract}
The wheat is one of the cereals more consumed in the human food in all worlds. In the form of flour it is used for preparation of breads, cookies, pizzas, cakes, and etc. This way, the knowledge of the mineral content this cereal and its flour is very important. Considering it, methods for determination of metals in these matrices are opportune and several papers have been performed.

In this paper, a slurry sampling flame atomic absorption spectrometric method for the determination of manganese in wheat flour is proposed. The optimization step was performed using univariate methodology involving the variables: nature and concentration of the acid solution for slurry preparation, sonication time and sample mass.

The established experimental conditions after optimization recommend a sample mass of $0.5 \mathrm{~g}, 2.0 \mathrm{~mol} \mathrm{~L}^{-1}$ nitric acid solution and a sonication time of $15 \mathrm{~min}$.

This method allows the determination of manganese in wheat flour using the standard calibration technique, with a detection limit of $0.13 \mu \mathrm{g} \mathrm{g}^{-1}$, and a precision, expressed as relative standard deviation (RSD) of $3.5 \%(n=10)$ for a manganese content of about $7.6 \mu \mathrm{g} \mathrm{g}^{-1}$ and using a wheat flour mass of $0.5 \mathrm{~g}$. The accuracy was confirmed by analyzing of three certified reference materials of rice flours.

The proposed method was applied for the determination of manganese in seven samples of wheat flour acquired in supermarkets from Salvador City, Brazil. In these, the manganese content varied of 5.2 and $7.6 \mu \mathrm{g} \mathrm{g}^{-1}$. The results showed no significant differences with those obtained after complete digestion of these samples and manganese determination also using FAAS.
\end{abstract}

(C) 2005 Elsevier Ltd. All rights reserved.

Keywords: Slurry sampling; Wheat flour; Manganese determination; FAAS

\section{Introduction}

Wheat is one of the cereals more consumed in the human foods. In the form of flour it is used for preparation of breads, cookies, pizzas, cakes and etc. This way, the knowledge of the mineral content this cereal and its flour is very important (Arredondo, Salva, Pizarro, \& Olivares, 2003; Ranum, 2005; Sebecic \& Vedrina-Dragojevic,

\footnotetext{
* Corresponding author. Tel./fax: +55 712355166.

E-mail address: slcf@ufba.br (S.L.C. Ferreira).
}

2004). Considering it, methods for determination of metals in these matrices are opportune and several papers have been published (Jacob \& Berndt, 2002; Shar, Kazi, Jakhrani, Sahito, \& Memon, 2002; Wang, Chen, Xie, Fan, \& $\mathrm{Wu}, 2004)$. In the last years, a variety of analytical methods have been performed involving the direct analysis of solid samples and also slurry sampling (Kurfürst, 1997). These methods present the followings advantages: simplification of sample pre-treatment, reduced risk of sample contamination, minimization of analyte losses during the pre-treatment operations or due to incomplete release of the analyte from the solid matrix, and no hazardous or corrosive 
reagents required. Slurry sampling has been used extensively during the last years for inductively coupled plasma optical emission spectrometry (ICP OES) (Ebdon, Foulkes, \& Sutton, 1997), electrothermal atomic absorption spectrometry (Amin, Kaneco, Suzuki, \& Ohta, 2003; Cal-Prieto et al., 2002) and ICP mass spectrometry (Maia, Pozebon, \& Curtius, 2003; Ribeiro, Vieira, \& Curtius, 2004). A method using hydride generation atomic fluorescence was also recently proposed for determination of selenium in milk (Rodenas-Torralba, Morales-Rubio, \& Dela-Guardia, 2005). Methods for analysis of wheat flour using slurry sampling ET AAS were performed for determination of selenium (Bendicho \& Sancho, 1993) and also nickel, chromium and cobalt (Gonzalez, Gallego, \& Valcarcel, 1999).

Slurry sampling methods using flame AAS (FAAS) are described less frequently in the literature (Alves, Cadore, Jardim, \& Arruda, 2001; DeAlmeida, Leandro, DaCosta, Santelli, \& DelaGuardia, 1997; Pereira, Berndt, \& Arruda, 2002; Quaresma, Cassella, \& De LaGuardia, 2004; Santos et al., in press), at least in part because of the limited sensitivity of this technique, and the risk of clogging the nebulizer capillary with sample particles.

Manganese is an inorganic nutrient involved in many important enzymes and/or proteins and thereby in many physiological functions of the organism. Deficiency signs include poor reproductive performance, growth retardation, congenital malformations in offspring, abnormal function of bone and cartilage and impaired glucose tolerance (Goldhaber, 2003). Several papers have been published involving the determination of manganese in food samples (Moreno-Rojas, Diaz-Valverde, Arroyo, Gonzalez, \& Capote, 2004; Nergiz \& Donmez, 2004; Turkekul, Elmastas, \& Tuzen, 2004).In the present paper, a slurry sampling FAAS method for the determination of manganese in wheat flour is proposed. The method was applied for manganese determination in wheat flour samples acquired in supermarkets from Salvador City, Brasil.

\section{Experimental}

\subsection{Instrumentation}

A Varian (Mulgrave, Victoria, Australia) Model SpectrAA 220 flame atomic absorption spectrometer was used for the analysis. The manganese hollow cathode lamp was operated with a current of $5.0 \mathrm{~mA}$. The most sensitive wavelength of manganese at $279.5 \mathrm{~nm}$ was used with a bandwidth of $0.2 \mathrm{~nm}$. The flame composition was: acetylene (flow rate $2.0 \mathrm{~L} \mathrm{~min}^{-1}$ ) and air (flow rate: 13.5 $\mathrm{L} \mathrm{min}^{-1}$ ); the burner height was $13.5 \mathrm{~mm}$, and the nebulizer flow rates were around $5.5-6.0 \mathrm{~mL} \mathrm{~min}^{-1}$. The medium particle size was measured using a Shimadzu (Kioto, Japan) Superscan SS-550 scanning electron microscope. An Ultrasonic Benchtop Cleaner VWR Model 75 D (Cortland, New York, USA) was used for slurry preparation.

\subsection{Reagents and samples}

All reagents were of analytical grade unless otherwise stated. Ultrapure water was obtained from an EASYpure RF (Barnstedt, Dubuque, IA, USA). Nitric and hydrochloric acid were of suprapur ${ }^{\circledR}$ quality (Merck). Laboratory glassware was kept overnight in 10\% (v/v) nitric acid. Before use the glassware was rinsed with deionized water and dried in a dust free environment.

Manganese solution $\left(100.0 \mu \mathrm{g} \mathrm{mL}^{-1}\right)$ was prepared by diluting a $1000 \mu \mathrm{g} \mathrm{mL}^{-1}$ manganese solution (Merck) with $1 \%(\mathrm{v} / \mathrm{v})$ hydrochloric acid.

The certified reference materials used for confirmation of the accuracy were: SRM 1568a rice flour (National Institute of Standard and Technology, NIST, Gaithersburg, MD, USA) and two CRM's rice flour (National Institute for Environmental Studies, NIES, Onogawa, Tsukuba, Japan).

The rice flour used for slurry preparation during the determination of the analytical features was MAIZENA ${ }^{\circledR}$ e DURYEA ${ }^{\circledR}$ (Unilever Bestfoods Brazil Ltda, Garanhuns, Pernanbuco, Brazil).

The wheat flour samples investigated in this study were locally available brands, collected in supermarkets from Salvador City, Brazil.

\section{Slurry preparation}

The slurries were prepared by placing $0.5 \mathrm{~g}$ of dried sample (medium size of the particles $\cong 18 \mu \mathrm{m}$ ) and $50.0 \mathrm{~mL}$ of $2.0 \mathrm{~mol} \mathrm{~L}^{-1}$ nitric acid solution in an ultrasonic bath for $15 \mathrm{~min}$. Afterwards, the slurries were aspirated directly through the nebulizer for manganese determination. The blanks were prepared in the same way as the slurries using a rice flour with manganese concentration lower than the limit of quantification of this method.

\subsection{Complete digestion of wheat flour samples}

For the acid digestion, about $0.5 \mathrm{~g}$ of the wheat flour samples, $5.0 \mathrm{~mL}$ of concentrated nitric acid and $1.0 \mathrm{~mL}$ of hydrogen peroxide were placed in a glass vessel and heated on a hot plate (in these conditions the samples are decomposed easily). Finally the content was quantitatively transfered to $10 \mathrm{~mL}$ volumetric flasks and diluted with water.

\section{Results and discussion}

\subsection{Optimization of the experimental conditions}

The optimization was performed using univariate methodology, involving the parameters: nature and concentration of the acid, sonication time and sample mass. All the experiments were performed using a slurry volume of $50 \mathrm{~mL}$. 
During the choice of the liquid phase for slurry preparation, hydrochloric and nitric acid solutions were tested. The results demonstrated that there is no difference in the analytical signals obtained for both acids, and that maximum sensitivity is obtained at a concentration of $1.0 \mathrm{~mol} \mathrm{~L}^{-1}$, which remains constant up to $4.0 \mathrm{~mol} \mathrm{~L}^{-1}$. However, a concentration of $2.0 \mathrm{~mol} \mathrm{~L}^{-1}$ nitric acid was used for slurry preparation in all further experiments, as slurries prepared with lower acid concentrations occasionally caused blockage of the nebulizer.

The sonication time was varied from 0 to $25 \mathrm{~min}$, and there was no influence from this parameter on the analytical signal obtained. However, it was observed that slurries prepared with sonication times of less than $10 \mathrm{~min}$ also caused occasional blockage of the nebulizer. For this reason, a sonication time of $15 \mathrm{~min}$ was used for all further investigations.

The sample mass for slurry preparation was varied between 200 and $1000 \mathrm{mg}$, using $50 \mathrm{~mL}$ of $2.0 \mathrm{~mol} \mathrm{~L}^{-1}$ nitric acid and a sonication time of $15 \mathrm{~min}$. The results showed that the slurries could be prepared without problems using up to $0.8 \mathrm{~g}$ of sample. The analytical signals obtained were linearly proportional with the sample mass. A sample mass of $0.5 \mathrm{~g}$ was used for all further investigations.

An additional experiment was carried out in order to investigate the extraction efficiency for manganese from the wheat flour samples, using the proposed method, i.e. $2.0 \mathrm{~mol} \mathrm{~L}^{-1}$ nitric acid and a sonication time of $15 \mathrm{~min}$. The absorbance obtained for the slurry was $0.0170 \pm 0.0002$. The absorbance obtained for the liquid phase of the same slurry after centrifugation for $10 \mathrm{~min}$ and filtration was $0.0147 \pm 0.0002$, demonstrating that the extraction process of manganese under these conditions was not complete $(\cong 86 \%)$. Hence it was necessary to use the slurry for complete recovery and not the liquid phase only.

\subsection{Analytical features}

The limit of detection (LOD) and quantification (LQ) were determined considering the standard deviation(s) of the blank (prepared in the same way as the samples as slurry using $0.5 \mathrm{~g}$ of MAIZENA ${ }^{\circledR}$ rice flour). The LOD and LQ obtained were 0.13 and $0.44 \mu \mathrm{g}$ of manganese per gram of wheat flour.

The precision calculated from 10 consecutive measurements of the slurry of a wheat flour sample with a manganese content of $7.6 \mu \mathrm{g} \mathrm{g}^{-1}$, expressed as relative standard deviation (RSD), was $3.5 \%$.

The calibration equations using aqueous standards $\left(\mathrm{A}=0.1831 \mathrm{C}_{\mathrm{Mn}}+0.0013\right)$, and for the analyte addition in wheat flour $\left(\mathrm{A}=0.1834 \mathrm{C}_{\mathrm{Mn}}+0.0084\right)$ and rice flour $\left(\mathrm{A}=0.1855 \mathrm{C}_{\mathrm{Mn}}+0.0002\right)$, exhibited very similar slopes, and the correlation coefficients were all $>0.999$. These results demonstrated that manganese in wheat flour samples can be directly determined using the standard calibration technique. The accuracy of the method was further
Table 1

Manganese determination in rice flour CRM

\begin{tabular}{lll}
\hline Rice flour CRM & Certified value $\left(\mu \mathrm{g} \mathrm{g}^{-1}\right)$ & Slurry method $\left(\mu \mathrm{g} \mathrm{g}^{-1}\right)$ \\
\hline NIST 1568a & $20.0 \pm 1.6$ & $19.2 \pm 0.6$ \\
NIES 1-a & $34.7 \pm 1.8$ & $34.3 \pm 0.6$ \\
NIES 1-c & $40.1 \pm 2.0$ & $38.3 \pm 0.3$ \\
\hline
\end{tabular}

Results expressed as interval confidence (at the 95\% level). Observation number $=3$. NIST: National Institute of Standard and Technology; NIES: National Institute for Environmental Studies.

Table 2

Manganese determination in wheat flour samples $(n=3)$

\begin{tabular}{lll}
\hline Sample & Complete digestion $\left(\mu \mathrm{g} \mathrm{g}^{-1}\right)$ & Slurry method $\left(\mu \mathrm{g} \mathrm{g}^{-1}\right)$ \\
\hline 1 & $5.8 \pm 0.3$ & $5.8 \pm 0.2$ \\
2 & $5.1 \pm 0.1$ & $5.2 \pm 0.7$ \\
3 & $5.8 \pm 0.4$ & $6.0 \pm 0.8$ \\
4 & $7.8 \pm 0.5$ & $7.6 \pm 0.5$ \\
5 & $5.4 \pm 0.1$ & $5.5 \pm 0.3$ \\
6 & $7.1 \pm 0.1$ & $7.3 \pm 0.6$ \\
7 & $5.9 \pm 0.4$ & $6.2 \pm 0.1$ \\
\hline
\end{tabular}

Results expressed as interval confidence (at the $95 \%$ level). Observation number $=3$.

confirmed by manganese determination in three certified reference materials (CRM) of rice flour. The results expressed as confidence interval (at the 95\% level) are shown in Table 1. The statistical comparison by $t$-test showed no significant difference between the manganese values obtained with the proposed method and the certified value for both CRM.

\subsection{Application}

The proposed method was applied for the determination of manganese in seven locally available powdered wheat flour samples, collected in supermarkets from Salvador City, Brazil. The results expressed as interval confidence (at the 95\% level) are summarized in Table 2. The manganese content found in these samples was between 5.2 and $7.6 \mu \mathrm{g}$ per gram of wheat flour. These samples were also analyzed after complete digestion (using nitric acid and hydrogen peroxide) and manganese determination by FAAS, and the results also are shown in Table 2. The $t$-test exhibited no significant difference between the manganese values obtained with the slurry method and those after complete digestion. The results achieved are close of data published in the literature (Santos, Lauria, \& Silveira, 2004).

\section{Conclusions}

The method proposed has limit of detection, precision and accuracy necessary for the determination of manganese in wheat flour samples. The use of the standard calibration technique with aqueous solutions makes the procedure quite simple and fast. The manganese content 
found in the wheat flour samples are close of data published in the literature.

\section{Acknowledgments}

The authors are grateful to Fundação de Amparo a Pesquisa do Estado da Bahia (FAPESB), Conselho Nacional de Desenvolvimento Científico e Tecnológico (CNPq) and Coordenação de Aperfeiçoamento de Pessoal de Nivel Superior (CAPES) for providing grants and fellowships and for financial support.

\section{References}

Alves, F. L., Cadore, S., Jardim, W. F., \& Arruda, M. A. Z. (2001). River sediment analysis by slurry sampling FAAS: determination of copper, zinc and lead. Journal of The Brazilian Chemical Society, 12(6), 799-803.

Amin, N., Kaneco, S., Suzuki, T., \& Ohta, K. (2003). Slurry sampling electrothermal atomic absorption spectrometric determination of copper in herbal medicine samples with a molybdenum tube atomizer. Microchemical Journal, 74(2), 181-186.

Arredondo, M., Salva, V., Pizarro, F., \& Olivares, M. (2003). Absorption of wheat flour fortified with reduced iron. Pediatric Research, 53(5), 873.

Bendicho, C., \& Sancho, A. (1993). Determination of selenium in wheatflour by GFAAS using automated ultrasonic slurry sampling. Atomic Spectroscopy, 14(6), 187-190.

Cal-Prieto, M. J., Felipe-Soleto, M., Carlosena, A., Andrade, J. M., Lopez-Mahia, P., Muniatequi, S., et al. (2002). Slurry sampling for direct analysis of solid materials by electrothermal atomic absorption spectrometry (ETAAS). A literature review from 1990 to 2000. Talanta, 56(1), 1-51.

DeAlmeida, M. D., Leandro, K. C., DaCosta, C. V., Santelli, R. E., \& DelaGuardia, M. (1997). Flow injection microwave-assisted dissolution of silicate rocks for magnesium determination by flame atomic absorption spectrometry. Journal of Analytical Atomic Spectrometry, 12(10), 1235-1238.

Ebdon, L., Foulkes, M., \& Sutton, K. (1997). Slurry nebulization in plasmas. Journal of Analytical Atomic Spectrometry, 12(2), 213-229.

Goldhaber, S. B. (2003). Trace element risk assessment: essentiality vs. toxicity. Regulatory Toxicology and Pharmacology, 38, 232-242.

Gonzalez, M., Gallego, M., \& Valcarcel, M. (1999). Determination of nickel, chromium and cobalt in wheat flour using slurry sampling electrothermal atomic absorption spectrometry. Talanta, 48(5), $1051-1060$

Jacob, P., \& Berndt, H. (2002). Online element determination in biological and environmental samples by flame AAS coupled with a hightemperature/high-pressure flow digestion system. Journal of Analytical Atomic Spectrometry, 17(12), 1615-1620.

Kurfürst, U. (1997). Solid sample analysis - Direct and slurry sampling using ETAAS and ETV-ICP. Heidelberg: Springer.
Maia, S. M., Pozebon, D., \& Curtius, A. J. (2003). Determination of Cd, $\mathrm{Hg}, \mathrm{Pb}$ and $\mathrm{Tl}$ in coal and coal fly ash slurries using electrothermal vaporization inductively coupled plasma mass spectrometry and isotopic dilution. Journal of Analytical Atomic Spectrometry, 18(4), 330-337.

Moreno-Rojas, R., Diaz-Valverde, M. A., Arroyo, B. M., Gonzalez, T. J., \& Capote, C. J. B. (2004). Mineral content of gurumelo (Amanita ponderosa). Food Chemistry, 85(3), 325-330.

Nergiz, C., \& Donmez, I. (2004). Chemical composition and nutritive value of Pinus pinea L. seeds. Food Chemistry, 86(3), 365368.

Pereira, E. R., Berndt, H., \& Arruda, M. A. Z. (2002). Simultaneous sample digestion and determination of $\mathrm{Cd}, \mathrm{Cu}$ and $\mathrm{Pb}$ in biological samples using thermospray flame furnace atomic absorption spectrometry (TS-FF-AAS) with slurry sample introduction. Journal of Analytical Atomic Spectrometry, 17(10), 1308-1315.

Quaresma, M. C. B., Cassella, R. J, \& De LaGuardia, M. (2004). Rapid on-line sample dissolution assisted by focused microwave radiation for silicate analysis employing flame atomic absorption spectrometry: iron determination. Talanta, 62(4), 807-811.

Ranum, P. (2005). Iron and folic acid fortification of wheat flour - the Cuernavaca consensus. Cereal Foods World, 50(2), 88-89.

Ribeiro, A. S., Vieira, M. A., \& Curtius, A. J. (2004). Determination of hydride forming elements ( $\mathrm{As}, \mathrm{Sb}, \mathrm{Se}, \mathrm{Sn}$ ) and $\mathrm{Hg}$ in environmental reference materials as acid slurries by on-line hydride generation inductively coupled plasma mass spectrometry. Spectrochimica Acta Part B: Atomic Spectroscopy, 59(2), 243-253.

Rodenas-Torralba, E., Morales-Rubio, A., \& Dela-Guardia, M. (2005). Multicommutation hydride generation atomic fluorescence determination of inorganic tellurium species in milk. Food Chemistry, 91(1), 181-189.

Santos, E. E., Lauria, D. C., \& Silveira, C. L. P. (2004). Assessment of daily intake of trace elements due to consumption of foodstuffs by adult inhabitants of Rio de Janeiro city. Science of the Total Environment, 327(1-3), 69-79.

Santos, W. N. L., Silva, E. G. P., Fernandes, M. S., Araujo, R. G. O., Costa, A. C. S., \& Vale, M. G. R., et al. (in press). Copper determination in powdered chocolate samples by slurry sampling flame atomic absorption spectrometry. Analytical and Bioanalytical Chemistry.

Sebecic, B., \& Vedrina-Dragojevic, I. (2004). Wheat flour confectionery products as a source of inorganic nutrients: zinc and copper contents in hard biscuits. Nahrung-Food, 48(2), 141-144.

Shar, G. Q., Kazi, T. G., Jakhrani, M. A., Sahito, S. R., \& Memon, M. A. (2002). Determination of seven heavy metals, cadmium, cobalt, chromium, nickel, lead, copper and manganese in wheat flour samples by flame atomic absorption spectrometry. Journal of the Chemical Society of Pakistan, 24(4), 265-268.

Turkekul, I., Elmastas, M., \& Tuzen, M. (2004). Determination of iron, copper, manganese, zinc, lead, and cadmium in mushroom samples from Tokat, Turkey. Food Chemistry, 84(3), 389-392.

Wang, X. M., Chen, Y. C., Xie, L. Q., Fan, Z. L., \& Wu, T. Y. (2004). Flame atomic absorption spectrophotometry for measurement of iron, manganese and zinc contents of wheat seeds. Spectroscopy and Spectral Analysis, 24(11), 1467-1469. 